\title{
Hybrid shrinking iterative solutions to convex feasibility problems for countable families of relatively nonexpansive mappings and a system of generalized mixed equilibrium problems
}

Wei-Qi Deng ${ }^{1 *}$ and Shanguang Qian²

*Correspondence:

dwq1273@126.com

'School of Statistics and

Mathematics, Yunnan University of Finance and Economics, Kunming,

Yunnan 650221, P.R. China

Full list of author information is

available at the end of the article

\begin{abstract}
We propose a new hybrid shrinking iterative scheme for approximating common elements of the set of solutions to convex feasibility problems for countable families of relatively nonexpansive mappings of a set of solutions to a system of generalized mixed equilibrium problems. A strong convergence theorem is established in the framework of Banach spaces. The results extend those of other authors, in which the involved mappings consist of just finitely many ones.

MSC: 47H09; 47H10;47J25
\end{abstract}

Keywords: relatively nonexpansive mappings; hybrid iteration scheme; convex feasibility problems; generalized mixed equilibrium problems

\section{Introduction}

Throughout this paper we assume that $E$ is a real Banach space with its dual $E^{*}, C$ is a nonempty, closed, convex subset of $E$, and $J: E \rightarrow 2^{E^{*}}$ is the normalized duality mapping defined by

$$
J x=\left\{f \in E^{*}:\langle x, f\rangle=\|x\|^{2}=\|f\|^{2}\right\}, \quad \forall x \in E .
$$

In the sequel, we use $F(T)$ to denote the set of fixed points of a mapping $T$. A point $p$ in $C$ is said to be an asymptotic fixed point of $T$ if $C$ contains a sequence $\left\{x_{n}\right\}$ which converges weakly to $p$ such that the $\lim _{n \rightarrow \infty}\left(x_{n}-T x_{n}\right)=0$. The set of asymptotic fixed points of $T$ will be denoted by $\hat{F}(T)$. A mapping $T: C \rightarrow C$ is said to be nonexpansive if

$$
\|T x-T y\| \leq\|x-y\|, \quad \forall x, y \in C .
$$

A mapping $T: C \rightarrow C$ is said to be relatively nonexpansive if $F(T)=\hat{F}(T) \neq \emptyset$ and

$$
\phi(p, T x) \leq \phi(p, x), \quad \forall x \in C, p \in F(T)
$$

๑ 2014 Deng and Qian; licensee Springer. This is an Open Access article distributed under the terms of the Creative Commons Attribution License (http://creativecommons.org/licenses/by/2.0), which permits unrestricted use, distribution, and reproduction in any medium, provided the original work is properly cited. 
where $\phi: E \times E \rightarrow \mathbb{R}^{1}$ denotes the Lyapunov functional defined by

$$
\phi(x, y)=\|x\|^{2}-2\langle x, J y\rangle+\|y\|^{2}, \quad \forall x, y \in E .
$$

It is obvious from the definition of $\phi$ that

$$
\begin{aligned}
& (\|x\|-\|y\|)^{2} \leq \phi(x, y) \leq(\|x\|+\|y\|)^{2}, \\
& \phi(x, y)=\phi(x, z)+\phi(z, y)+2\langle x-z, J z-J y\rangle,
\end{aligned}
$$

and

$$
\phi(x, y)=\langle x, J x-J y\rangle+\langle y-x, J y\rangle \leq\|x\|\|J x-J y\|+\|y-x\|\|y\| .
$$

The asymptotic behavior of a relatively nonexpansive mapping was studied in [1-4]. In 1953, Mann [5] introduced the iteration as follows: a sequence $\left\{x_{n}\right\}$ is defined by

$$
x_{n+1}=\alpha_{n} x_{n}+\left(1-\alpha_{n}\right) T x_{n}
$$

where the initial element $x_{0} \in C$ is arbitrary and $\left\{\alpha_{n}\right\}$ is a sequence of real numbers in $[0,1]$. The Mann iteration has been extensively investigated for nonexpansive mappings. One of the fundamental convergence results was proved by Reich [6]. In an infinite-dimensional Hilbert space, a Mann iteration can yield only weak convergence (see [7, 8]). Attempts to modify the Mann iteration method (1.8) so that strong convergence is guaranteed have recently been made. Nakajo and Takahashi [9] proposed the following modification of Mann iteration method (1.8) for a nonexpansive mapping $T$ from $C$ into itself in a Hilbert space: from an arbitrary $x_{0} \in C$,

$$
\left\{\begin{array}{l}
y_{n}=\alpha_{n} x_{n}+\left(1-\alpha_{n}\right) T x_{n}, \\
C_{n}=\left\{z \in C:\left\|y_{n}-z\right\| \leq\left\|x_{n}-z\right\|\right\}, \\
Q_{n}=\left\{z \in C:\left\langle x_{n}-z, x_{0}-x_{n}\right\rangle \geq 0\right\}, \\
x_{n+1}=P_{C_{n} \cap Q_{n}} x_{0}, \quad \forall n \in \mathbb{N} \cup\{0\},
\end{array}\right.
$$

where $P_{K}$ denotes the metric projection from a Hilbert space $H$ onto a closed convex subset $K$ of $H$ and proved that the sequence $\left\{x_{n}\right\}$ converges strongly to $P_{F(T)} x_{0}$. A projection onto the intersection of two half-spaces is computed by solving a linear system of two equations with two unknowns (see [10, Section 3]).

Let $\theta: C \times C \rightarrow \mathbb{R}^{1}$ be a bifunction, $\psi: C \rightarrow \mathbb{R}^{1}$ a real-valued function, and $B: C \rightarrow E^{*}$ a nonlinear mapping. The so-called generalized mixed equilibrium problem (GMEP) is to find an $u \in C$ such that

$$
\theta(u, y)+\langle y-u, B u\rangle+\psi(y)-\psi(u) \geq 0, \quad \forall y \in C,
$$

whose set of solutions is denoted by $\Omega(\theta, B, \psi)$.

The equilibrium problem is a unifying model for several problems arising in physics, engineering, science optimization, economics, transportation, network and structural analysis, Nash equilibrium problems in noncooperative games, and others. It has been shown 
that variational inequalities and mathematical programming problems can be viewed as a special realization of the abstract equilibrium problems. Many authors have proposed some useful methods to solve the EP (equilibrium problem), GEP (generalized equilibrium problem), MEP (mixed equilibrium problem), and GMEP.

In 2007, Plubtieng and Ungchittrakool [11] established strong convergence theorems for a common fixed point of two relatively nonexpansive mappings in a Banach space by using the following hybrid method in mathematical programming:

$$
\left\{\begin{array}{l}
x_{0}=x \in C, \\
y_{n}=J^{-1}\left[\alpha_{n} J x_{n}+\left(1-\alpha_{n}\right) J z_{n}\right], \\
z_{n}=J^{-1}\left[\beta_{n}^{(1)} J x_{n}+\beta_{n}^{(2)} J T x_{n}+\beta_{n}^{(3)} J S x_{n}\right], \\
H_{n}=\left\{z \in C: \phi\left(z, y_{n}\right) \leq \phi\left(z, x_{n}\right)\right\}, \\
W_{n}=\left\{z \in C:\left\langle x_{n}-z, J x-J y\right\rangle \geq 0\right\}, \\
x_{n+1}=P_{H_{n} \cap W_{n}} x, \quad \forall n \in \mathbb{N} \cup\{0\} .
\end{array}\right.
$$

Their results extended and improved the corresponding ones announced by Nakajo and Takahashi [9], Martinez-Yanes and Xu [12], and Matsushita and Takahashi [4].

Recently, Su and Qin [13] modified iteration (1.9), the so-called monotone CQ method for nonexpansive mapping, as follows: from an arbitrary $x_{0} \in C$,

$$
\left\{\begin{array}{l}
y_{n}=\alpha_{n} x_{n}+\left(1-\alpha_{n}\right) T x_{n}, \\
C_{0}=\left\{z \in C:\left\|y_{0}-z\right\| \leq\left\|x_{0}-z\right\|\right\}, \quad Q_{0}=C, \\
C_{n}=\left\{z \in C_{n-1} \cap Q_{n-1}:\left\|y_{n}-z\right\| \leq\left\|x_{n}-z\right\|\right\}, \\
Q_{n}=\left\{z \in C_{n-1} \cap Q_{n-1}:\left\langle x_{n}-z, x_{0}-x_{n}\right\rangle \geq 0\right\}, \\
x_{n+1}=P_{C_{n} \cap Q_{n}} x_{0}, \quad \forall n \in \mathbb{N} \cup\{0\},
\end{array}\right.
$$

and proved that the sequence $\left\{x_{n}\right\}$ converges strongly to $P_{F(T)} x_{0}$.

Inspired and motivated by the studies mentioned above, in this paper, we use a modified hybrid iteration scheme for approximating common elements of the set of solutions to convex feasibility problem for a countable families of relatively nonexpansive mappings, of set of solutions to a system of generalized mixed equilibrium problems. A strong convergence theorem is established in the framework of Banach spaces. The results extend those of the authors, in which the involved mappings consist of just finitely many ones.

\section{Preliminaries}

We say that $E$ is strictly convex if the following implication holds for $x, y \in E$ :

$$
\|x\|=\|y\|=1, \quad x \neq y \quad \Rightarrow \quad\left\|\frac{x+y}{2}\right\|<1 .
$$

It is also said to be uniformly convex if for any $\epsilon>0$, there exists $\delta>0$ such that

$$
\|x\|=\|y\|=1, \quad\|x-y\| \geq \epsilon \quad \Rightarrow \quad\left\|\frac{x+y}{2}\right\| \leq 1-\delta .
$$

It is well known that if $E$ is a uniformly convex Banach space, then $E$ is reflexive and strictly convex. A Banach space $E$ is said to be smooth if

$$
\lim _{t \rightarrow 0} \frac{\|x+t y\|-\|x\|}{t}
$$


exists for each $x, y \in S(E):=\{x \in E:\|x\|=1\}$. E is said to be uniformly smooth if the limit (2.3) is attained uniformly for $x, y \in S(E)$.

Following Alber [14], the generalized projection $P_{C}: E \rightarrow C$ is defined by

$$
P_{C}=\arg \inf _{y \in C} \phi(y, x), \quad \forall x \in E .
$$

Lemma 2.1 [14] Let E be a smooth, strictly convex and reflexive Banach space and C be a nonempty, closed, convex subset of $E$. Then the following conclusions hold:

(1) $\phi\left(x, P_{C} y\right)+\phi\left(P_{C} y, y\right) \leq \phi(x, y)$ for all $x \in C$ and $y \in E$.

(2) If $x \in E$ and $z \in C$, then $z=P_{C} x \Leftrightarrow\langle z-y, J x-J z\rangle \geq 0, \forall y \in C$.

(3) For $x, y \in E, \phi(x, y)=0$ if and only if $x=y$.

Lemma 2.2 [15] Let E be a uniformly convex and smooth Banach space and let $r>0$. Then there exists a continuous, strictly increasing, and convex function $h:[0,2 r] \rightarrow[0, \infty)$ such that $h(0)=0$ and

$$
h(\|x\|-\|y\|) \leq \phi(x, y)
$$

for all $x, y \in B_{r}:=\{z \in E:\|z\| \leq r\}$

Lemma 2.3 [16] Let E be a uniformly convex and smooth Banach space and let $\left\{x_{n}\right\}$ and $\left\{y_{n}\right\}$ be two sequences of $E$. If $\phi\left(x_{n}, y_{n}\right) \rightarrow 0$, where $\phi$ is the function defined by (1.4), and either $\left\{x_{n}\right\}$ or $\left\{y_{n}\right\}$ is bounded, then $\left\|x_{n}-y_{n}\right\| \rightarrow 0$.

Remark 2.4 The following basic properties for a Banach space $E$ can be found in Cioranescu [17].

(i) If $E$ is uniformly smooth, then $J$ is uniformly continuous on each bounded subset of $E$.

(ii) If $E$ is reflexive and strictly convex, then $J^{-1}$ is norm-weak-continuous.

(iii) If $E$ is a smooth, strictly convex and reflexive Banach space, then the normalized duality mapping $J: E \rightarrow 2^{E^{*}}$ is single valued, one-to-one, and onto.

(iv) A Banach space $E$ is uniformly smooth if and only if $E^{*}$ is uniformly convex.

(v) Each uniformly convex Banach space $E$ has the Kadec-Klee property, i.e., for any sequence $\left\{x_{n}\right\} \subset E$, if $x_{n} \rightarrow x \in E$ and $\left\|x_{n}\right\| \rightarrow\|x\|$, then $x_{n} \rightarrow x$ as $n \rightarrow \infty$.

Lemma 2.5 [18] Let E be a real uniformly convex Banach space and let $B_{r}(0)$ be the closed ball of $E$ with center at the origin and radius $r>0$. Then there exists a continuous strictly increasing convex function $g:[0, \infty) \rightarrow[0, \infty)$ with $g(0)=0$ such that

$$
\|\lambda x+\mu y+\gamma z\|^{2} \leq \lambda\|x\|^{2}+\mu\|y\|^{2}+\gamma\|z\|^{2}-\lambda \mu g(\|x-y\|)
$$

for all $x, y, z \in B_{r}(0)$ and $\lambda, \mu, \gamma \in[0,1]$ with $\lambda+\mu+\gamma=1$.

Lemma 2.6 [19] The unique solutions to the positive integer equation

$$
n=i_{n}+\frac{\left(m_{n}-1\right) m_{n}}{2}, \quad m_{n} \geq i_{n}, n=1,2,3, \ldots
$$


are

$$
i_{n}=n-\frac{\left(m_{n}-1\right) m_{n}}{2}, \quad m_{n}=-\left[\frac{1}{2}-\sqrt{2 n+\frac{1}{4}}\right], n=1,2,3, \ldots
$$

where $[x]$ denotes the maximal integer that is not larger than $x$.

\section{Main results}

Theorem 3.1 Let E be a real uniformly smooth and strictly convex Banach space, and $C$ be a nonempty, closed, convex subset of $E$. Let $\left\{T_{i}\right\}: C \rightarrow C$ and $\left\{S_{i}\right\}: C \rightarrow C$ be two sequences of relatively nonexpansive mappings with $F:=\bigcap_{i=1}^{\infty}\left(F\left(T_{i}\right) \cap F\left(S_{i}\right)\right) \neq \emptyset$. Let $\left\{x_{n}\right\}$ be the sequence generated by

$$
\left\{\begin{array}{l}
x_{0}=x \in C, \quad H_{-1}=W_{-1}=C, \\
y_{n}=J^{-1}\left[\lambda_{n} J x_{n}+\left(1-\lambda_{n}\right) J z_{n}\right], \\
z_{n}=J^{-1}\left[\alpha_{n} J x_{n}+\beta_{n} J T_{i_{n}} x_{n}+\gamma_{n} J S_{i_{n}} x_{n}\right], \\
H_{n}=\left\{z \in H_{n-1} \cap W_{n-1}: \phi\left(z, y_{n}\right) \leq \phi\left(z, x_{n}\right)\right\}, \\
W_{n}=\left\{z \in H_{n-1} \cap W_{n-1}:\left\langle x_{n}-z, J x-J y\right\rangle \geq 0\right\}, \\
x_{n+1}=P_{H_{n} \cap W_{n}} x, \quad \forall n \in \mathbb{N} \cup\{0\},
\end{array}\right.
$$

where $\left\{\lambda_{n}\right\},\left\{\alpha_{n}\right\},\left\{\beta_{n}\right\}$, and $\left\{\gamma_{n}\right\}$ are sequences in $[0,1]$ satisfying

(1) $0 \leq \lambda_{n}<1, \forall n \in \mathbb{N} \cup\{0\}$; $\limsup _{n \rightarrow \infty} \lambda_{n}<1$;

(2) $\alpha_{n}+\beta_{n}+\gamma_{n}=1 ; \lim _{n \rightarrow \infty} \alpha_{n}=0$ and $\liminf _{n \rightarrow \infty} \beta_{n} \gamma_{n}>0$;

and $i_{n}$ is the solution to the positive integer equation $n=i_{n}+\frac{\left(m_{n}-1\right) m_{n}}{2}\left(m_{n} \geq i_{n}, n=1,2, \ldots\right)$, that is, for each $n \geq 1$, there exists a unique $i_{n}$ such that

$$
\begin{aligned}
& i_{1}=1, \quad i_{2}=1, \quad i_{3}=2, \quad i_{4}=1, \quad i_{5}=2, \quad i_{6}=3 \text {, } \\
& i_{7}=1, \quad i_{8}=2, \quad i_{9}=3, \quad i_{10}=4, \quad i_{11}=1, \quad \ldots
\end{aligned}
$$

Then $\left\{x_{n}\right\}$ converges strongly to $P_{F} x$, where $P_{F} x$ is the generalized projection from $C$ onto $F$.

Proof We divide the proof into several steps.

(I) $H_{n}$ and $W_{n}(\forall n \in \mathbb{N} \cup\{0\})$ both are closed and convex subsets in $C$.

This follows from the fact that $\phi\left(z, y_{n}\right) \leq \phi\left(z, x_{n}\right)$ is equivalent to

$$
2\left\langle z, J x_{n}-J y_{n}\right\rangle \leq\left\|x_{n}\right\|^{2}-\left\|y_{n}\right\|^{2}
$$

(II) $F$ is a subset of $\bigcap_{n=0}^{\infty}\left(H_{n} \cap W_{n}\right)$.

In fact, we note by [4, Proposition 2.4] that for each $i \geq 1, F\left(S_{i}\right)$ and $F\left(T_{i}\right)$ are closed convex sets and so is $F$. It is clear that $F \subset C=H_{-1} \cap W_{-1}$. Suppose that $F \subset C_{n-1} \cap Q_{n-1}$ for some $n \in \mathbb{N}$. For any $u \in F$, by the convexity of $\|\cdot\|^{2}$, we have

$$
\begin{aligned}
\phi\left(u, z_{n}\right)= & \phi\left(u, J^{-1}\left[\alpha_{n} J x_{n}+\beta_{n} J T_{i_{n}} x_{n}+\gamma_{n} J S_{i_{n}} x_{n}\right]\right) \\
= & \|u\|^{2}-2\left\langle u, \alpha_{n} J x_{n}+\beta_{n} J T_{i_{n}} x_{n}+\gamma_{n} J S_{i_{n}} x_{n}\right\rangle \\
& +\left\|\alpha_{n} J x_{n}+\beta_{n} J T_{i_{n}} x_{n}+\gamma_{n} J S_{i_{n}} x_{n}\right\|^{2} \\
\leq & \|u\|^{2}-2 \alpha_{n}\left\langle u, J x_{n}\right\rangle-2 \beta_{n}\left\langle u, J T_{i_{n}} x_{n}\right\rangle-2 \gamma_{n}\left\langle u, J S_{i_{n}} x_{n}\right\rangle
\end{aligned}
$$




$$
\begin{aligned}
& +\alpha_{n}\left\|x_{n}\right\|^{2}+\beta_{n}\left\|T_{i_{n}} x_{n}\right\|^{2}+\gamma_{n}\left\|S_{i_{n}} x_{n}\right\|^{2} \\
= & \alpha_{n} \phi\left(u, x_{n}\right)+\beta_{n} \phi\left(u, T_{i_{n}} x_{n}\right)+\gamma_{n} \phi\left(u, S_{i_{n}} x_{n}\right) \\
\leq & \alpha_{n} \phi\left(u, x_{n}\right)+\beta_{n} \phi\left(u, x_{n}\right)+\gamma_{n} \phi\left(u, x_{n}\right) \\
= & \phi\left(u, x_{n}\right),
\end{aligned}
$$

and then

$$
\begin{aligned}
\phi\left(u, y_{n}\right) & =\phi\left(u, J^{-1}\left[\lambda_{n} J x_{n}+\left(1-\lambda_{n}\right) J z_{n}\right]\right) \\
& =\|u\|^{2}-2\left\langle u, \lambda_{n} J x_{n}+\left(1-\lambda_{n}\right) J z_{n}\right\rangle+\left\|\lambda_{n} J x_{n}+\left(1-\lambda_{n}\right) J z_{n}\right\|^{2} \\
& \leq\|u\|^{2}-2 \lambda_{n}\left\langle u, J x_{n}\right\rangle-2\left(1-\lambda_{n}\right)\left\langle u, J z_{n}\right\rangle+\lambda_{n}\left\|x_{n}\right\|^{2}+\left(1-\lambda_{n}\right)\left\|z_{n}\right\|^{2} \\
& =\lambda_{n}\left(\|u\|^{2}-2\left\langle u, J x_{n}\right\rangle+\left\|x_{n}\right\|^{2}\right)+\left(1-\lambda_{n}\right)\left(\|u\|^{2}-2\left\langle u, J z_{n}\right\rangle+\left\|z_{n}\right\|^{2}\right) \\
& =\lambda_{n} \phi\left(u, x_{n}\right)+\left(1-\lambda_{n}\right) \phi\left(u, z_{n}\right) \\
& \leq \lambda_{n} \phi\left(u, x_{n}\right)+\left(1-\lambda_{n}\right) \phi\left(u, x_{n}\right) \\
& =\phi\left(u, x_{n}\right) .
\end{aligned}
$$

This implies that $F \subset H_{n}$. It follows from $x_{n}=P_{H_{n-1} \cap W_{n-1}} x$ and Lemma 2.1(2) that

$$
\left\langle x_{n}-z, J x-J x_{n}\right\rangle \geq 0, \quad \forall z \in H_{n-1} \cap W_{n-1} .
$$

Particularly,

$$
\left\langle x_{n}-z, J x-J x_{n}\right\rangle \geq 0, \quad \forall u \in F,
$$

and hence $F \subset W_{n}$, which yields $F \subset H_{n} \cap W_{n}$. By induction, $F \subset \bigcap_{n=0}^{\infty}\left(H_{n} \cap W_{n}\right)$.

(III) $\lim _{n \rightarrow \infty}\left\|x_{n}-T_{i_{n}} x_{n}\right\|=\lim _{n \rightarrow \infty}\left\|x_{n}-S_{i_{n}} x_{n}\right\|=0$.

In view of $x_{n+1}=P_{H_{n} \cap W_{n}} x \in H_{n}$ and the definition of $H_{n}$, we also have

$$
\phi\left(x_{n+1}, y_{n}\right) \leq \phi\left(x_{n+1}, x_{n}\right), \quad \forall n \in \mathbb{N} \text {. }
$$

This implies that

$$
\lim _{n \rightarrow \infty} \phi\left(x_{n+1}, y_{n}\right)=\lim _{n \rightarrow \infty} \phi\left(x_{n+1}, x_{n}\right)=0 .
$$

It follows from Lemma 2.2 that

$$
\lim _{n \rightarrow \infty}\left\|x_{n+1}-y_{n}\right\|=\lim _{n \rightarrow \infty}\left\|x_{n+1}-x_{n}\right\|=0 .
$$

Since $J$ is uniformly norm-to-norm continuous on bounded sets, we have

$$
\lim _{n \rightarrow \infty}\left\|J x_{n+1}-J y_{n}\right\|=\lim _{n \rightarrow \infty}\left\|J x_{n+1}-J x_{n}\right\|=0
$$

and

$$
\left\|J x_{n+1}-J y_{n}\right\| \geq\left(1-\lambda_{n}\right)\left\|J x_{n+1}-J z_{n}\right\|-\lambda_{n}\left\|J x_{n+1}-J x_{n}\right\|, \quad \forall n \in \mathbb{N} \cup\{0\}
$$


This implies that

$$
\begin{aligned}
\left\|J x_{n+1}-J z_{n}\right\| & \leq \frac{1}{1-\lambda_{n}}\left(\left\|J x_{n+1}-J y_{n}\right\|+\lambda_{n}\left\|J x_{n+1}-J x_{n}\right\|\right) \\
& \leq \frac{1}{1-\lambda_{n}}\left(\left\|J x_{n+1}-J y_{n}\right\|+\left\|J x_{n+1}-J x_{n}\right\|\right) .
\end{aligned}
$$

From (3.10) and $\lim \sup _{n \rightarrow \infty} \lambda_{n}<1$, we have $\lim _{n \rightarrow \infty}\left\|J x_{n+1}-J z_{n}\right\|=0$. Since $J^{-1}$ is also uniformly norm-to-norm continuous on bounded sets, we obtain

$$
\lim _{n \rightarrow \infty}\left\|x_{n+1}-z_{n}\right\|=\lim _{n \rightarrow \infty}\left\|J^{-1}\left(J x_{n+1}\right)-J^{-1}\left(J z_{n}\right)\right\|=0
$$

From $\left\|x_{n}-z_{n}\right\| \leq\left\|x_{n}-x_{n+1}\right\|+\left\|x_{n+1}-z_{n}\right\|$ we have $\lim _{n \rightarrow \infty}\left\|x_{n}-z_{n}\right\|=0$. Since $\left\{x_{n}\right\}$ is bounded, $\phi\left(p, T_{i_{n}} x_{n}\right) \leq \phi\left(p, x_{n}\right)$ and $\phi\left(p, S_{i_{n}} x_{n}\right) \leq \phi\left(p, x_{n}\right)$ for any $p \in F$. We also find that $\left\{J x_{n}\right\},\left\{J T_{i_{n}} x_{n}\right\}$ and $\left\{J S_{i_{n}} x_{n}\right\}$ are bounded, and then there exists an $r>0$ such that $\left\{J x_{n}\right\},\left\{J T_{i_{n}} x_{n}\right\},\left\{J S_{i_{n}} x_{n}\right\} \subset B_{r}(0)$. Therefore Lemma 2.5 is applicable and we observe that

$$
\begin{aligned}
\phi\left(p, z_{n}\right)= & \|p\|^{2}-2\left\langle p, \alpha_{n} J x_{n}+\beta_{n} J T_{i_{n}} x_{n}+\gamma_{n} J S_{i_{n}} x_{n}\right\rangle \\
& +\left\|\alpha_{n} J x_{n}+\beta_{n} J T_{i_{n}} x_{n}+\gamma_{n} J S_{i_{n}} x_{n}\right\|^{2} \\
\leq & \|p\|^{2}-2 \alpha_{n}\left\langle p, J x_{n}\right\rangle-2 \beta_{n}\left\langle p, J T_{i_{n}} x_{n}\right\rangle-2 \gamma_{n}\left\langle p, J S_{i_{n}} x_{n}\right\rangle \\
& +\alpha_{n}\left\|x_{n}\right\|^{2}+\beta_{n}\left\|T_{i_{n}} x_{n}\right\|^{2}+\gamma_{n}\left\|S_{i_{n}} x_{n}\right\|^{2}-\beta_{n} \gamma_{n} g\left(\left\|J T_{i_{n}} x_{n}-J S_{i_{n}} x_{n}\right\|\right) \\
= & \alpha_{n} \phi\left(p, x_{n}\right)+\beta_{n} \phi\left(p, T_{i_{n}} x_{n}\right)+\gamma_{n} \phi\left(p, S_{i_{n}} x_{n}\right)-\beta_{n} \gamma_{n} g\left(\left\|J T_{i_{n}} x_{n}-J S_{i_{n}} x_{n}\right\|\right) \\
\leq & \phi\left(p, x_{n}\right)-\beta_{n} \gamma_{n} g\left(\left\|J T_{i_{n}} x_{n}-J S_{i_{n}} x_{n}\right\|\right) .
\end{aligned}
$$

That is,

$$
\beta_{n} \gamma_{n} g\left(\left\|J T_{i_{n}} x_{n}-J S_{i_{n}} x_{n}\right\|\right) \leq \phi\left(p, x_{n}\right)-\phi\left(p, z_{n}\right)
$$

where $g:[0, \infty) \rightarrow[0, \infty)$ is a continuous strictly convex function with $g(0)=0$.

Let $\left\{\left\|T_{i_{n_{k}}} x_{n_{k}}-S_{i_{n_{k}}} x_{n_{k}}\right\|\right\}$ be any subsequence of $\left\{\left\|T_{i_{n}} x_{n}-S_{i_{n}} x_{n}\right\|\right\}$. Since $\left\{x_{n_{k}}\right\}$ is bounded, there exists a subsequence $\left\{x_{n_{j}}\right\}$ of $\left\{x_{n_{k}}\right\}$ such that for any $p \in F$,

$$
\lim _{j \rightarrow \infty} \phi\left(p, x_{n_{j}}\right)=\limsup _{k \rightarrow \infty} \phi\left(p, x_{n_{k}}\right):=a .
$$

From (1.6) we have

$$
\begin{aligned}
\phi\left(p, x_{n_{j}}\right) & =\phi\left(p, z_{n_{j}}\right)+\phi\left(z_{n_{j}}, x_{n_{j}}\right)+2\left\langle p-z_{n_{j}}, J z_{n_{j}}-J x_{n_{j}}\right\rangle \\
& \leq \phi\left(p, z_{n_{j}}\right)+\phi\left(z_{n_{j}}, x_{n_{j}}\right)+M\left\|J z_{n_{j}}-J x_{n_{j}}\right\|
\end{aligned}
$$

for some appropriate constant $M>0$. Since

$$
\lim _{j \rightarrow \infty} \phi\left(z_{n_{j}}, x_{n_{j}}\right)=0=\lim _{j \rightarrow \infty}\left\|J z_{n_{j}}-J x_{n_{j}}\right\|
$$


it follows that

$$
a=\liminf _{j \rightarrow \infty} \phi\left(p, x_{n_{j}}\right) \leq \liminf _{j \rightarrow \infty} \phi\left(p, z_{n_{j}}\right) .
$$

From (3.3), we have

$$
\limsup _{j \rightarrow \infty} \phi\left(p, z_{n_{j}}\right) \leq \limsup _{j \rightarrow \infty} \phi\left(p, x_{n_{j}}\right)=a
$$

and hence $\lim _{j \rightarrow \infty} \phi\left(p, x_{n_{j}}\right)=a=\lim _{j \rightarrow \infty} \phi\left(p, z_{n_{j}}\right)$. By (3.15), we observe that, as $j \rightarrow \infty$,

$$
\beta_{n_{j}} \gamma_{n_{j}} g\left(\left\|J T_{i_{n_{j}}} x_{n_{j}}-J S_{i_{n_{j}}} x_{n_{j}}\right\|\right) \leq \phi\left(p, x_{n_{j}}\right)-\phi\left(p, z_{n_{j}}\right) \rightarrow 0
$$

Since $\liminf _{n \rightarrow \infty} \beta_{n} \gamma_{n}>0$, it follows that $\lim _{j \rightarrow \infty} g\left(\left\|J T_{i_{n_{j}}} x_{n_{j}}-J S_{i_{n_{j}}} x_{n_{j}}\right\|\right)=0$. By the properties of the mapping $g$, we have $\lim _{j \rightarrow \infty}\left\|J T_{i_{n_{j}}} x_{n_{j}}-J S_{i_{n_{j}}} x_{n_{j}}\right\|=0$. Since $J^{-1}$ is also uniformly norm-to-norm continuous on bounded sets, we obtain

$$
\lim _{j \rightarrow \infty}\left\|T_{i_{n_{j}}} x_{n_{j}}-S_{i_{n_{j}}} x_{n_{j}}\right\|=\lim _{j \rightarrow \infty}\left\|J^{-1}\left(J T_{i_{n_{j}}} x_{n_{j}}\right)-J^{-1}\left(J S_{i_{n_{j}}} x_{n_{j}}\right)\right\|=0,
$$

and then $\lim _{n \rightarrow \infty}\left\|T_{i_{n}} x_{n}-S_{i_{n}} x_{n}\right\|=0$. Next, we note by the convexity of $\|\cdot\|^{2}$ and (1.7) that, as $n \rightarrow \infty$,

$$
\begin{aligned}
\phi\left(T_{i_{n}} x_{n}, z_{n}\right)= & \left\|T_{i_{n}} x_{n}\right\|^{2}-2\left\langle T_{i_{n}} x_{n}, \alpha_{n} J x_{n}+\beta_{n} J T_{i_{n}} x_{n}+\gamma_{n} J S_{i_{n}} x_{n}\right\rangle \\
& +\left\|\alpha_{n} J x_{n}+\beta_{n} J T_{i_{n}} x_{n}+\gamma_{n} J S_{i_{n}} x_{n}\right\|^{2} \\
\leq & \left\|T_{i_{n}} x_{n}\right\|^{2}-2 \alpha_{n}\left\langle T_{i_{n}} x_{n}, J x_{n}\right\rangle-2 \beta_{n}\left\langle T_{i_{n}} x_{n}, J T_{i_{n}} x_{n}\right\rangle-2 \gamma_{n}\left\langle T_{i_{n}} x_{n}, J S_{i_{n}} x_{n}\right\rangle \\
& +\alpha_{n}\left\|x_{n}\right\|^{2}+\beta_{n}\left\|T_{i_{n}} x_{n}\right\|^{2}+\gamma_{n}\left\|S_{i_{n}} x_{n}\right\|^{2} \\
= & \alpha_{n} \phi\left(T_{i_{n}} x_{n}, x_{n}\right)+\beta_{n} \phi\left(T_{i_{n}} x_{n}, S_{i_{n}} x_{n}\right) \rightarrow 0,
\end{aligned}
$$

since $\alpha_{n} \rightarrow 0$. By Lemma 2.3, we have $\lim _{n \rightarrow \infty}\left\|T_{i_{n}} x_{n}-z_{n}\right\|=0$ and hence

$$
\left\|T_{i_{n}} x_{n}-x_{n}\right\| \leq\left\|T_{i_{n}} x_{n}-z_{n}\right\|+\left\|z_{n}-x_{n}\right\| \rightarrow 0
$$

as $n \rightarrow \infty$. Moreover, we observe that

$$
\left\|S_{i_{n}} x_{n}-x_{n}\right\| \leq\left\|S_{i_{n}} x_{n}-T_{i_{n}} x_{n}\right\|+\left\|T_{i_{n}} x_{n}-x_{n}\right\| \rightarrow 0
$$

as $n \rightarrow \infty$.

(IV) $x_{n} \rightarrow P_{F} x$ as $n \rightarrow \infty$.

It follows from the definition of $W_{n}$ and Lemma 2.1(2) that $x_{n}=P_{W_{n}} x$. Since $x_{n+1}=$ $P_{H_{n} \cap W_{n}} x \in W_{n}$, we have

$$
\phi\left(x_{n}, x\right) \leq \phi\left(x_{n+1}, x\right), \quad \forall n \geq 1 .
$$

Therefore, $\left\{\phi\left(x_{n}, x\right)\right\}$ is nondecreasing. Using $x_{n}=P_{W_{n}} x$ and Lemma 2.1(1), we have

$$
\phi\left(x_{n}, x\right)=\phi\left(P_{W_{n}} x, x\right) \leq \phi(p, x)-\phi\left(p, x_{n}\right) \leq \phi(p, x)
$$


for all $p \in F$ and for all $n \in \mathbb{N}$, that is, $\left\{\phi\left(x_{n}, x\right)\right\}$ is bounded. Then

$$
\lim _{n \rightarrow \infty} \phi\left(x_{n}, x\right) \text { exists. }
$$

In particular, by (1.5), the sequence $\left\{\left(\left\|x_{n}\right\|-\|x\|\right)^{2}\right\}$ is bounded. This implies that $\left\{x_{n}\right\}$ is bounded. Note again that $x_{n}=P_{W_{n}} x$ and for any positive integer $k, x_{n+k} \in W_{n+k-1} \subset W_{n}$. By Lemma 2.1(1),

$$
\begin{aligned}
\phi\left(x_{n+k}, x_{n}\right) & =\phi\left(x_{n+k}, P_{W_{n}} x\right) \\
& \leq \phi\left(x_{n+k}, x\right)-\phi\left(P_{W_{n}} x, x\right) \\
& =\phi\left(x_{n+k}, x\right)-\phi\left(x_{n}, x\right) .
\end{aligned}
$$

By Lemma 2.2, we have, for $m, n \in \mathbb{N}$ with $m>n$,

$$
h\left(\left\|x_{m}-x_{n}\right\|\right) \leq \phi\left(x_{m}, x_{n}\right) \leq \phi\left(x_{m}, x\right)-\phi\left(x_{n}, x\right)
$$

where $h:[0, \infty) \rightarrow[0, \infty)$ is a continuous, strictly increasing, and convex function with $h(0)=0$. Then the properties of the function g show that $\left\{x_{n}\right\}$ is a Cauchy sequence in $C$, so there exists $x^{*} \in C$ such that

$$
x_{n} \rightarrow x^{*} \quad(n \rightarrow \infty) .
$$

Now, set $\mathbb{N}_{i}=\left\{k \in \mathbb{N}: k=i+\frac{(m-1) m}{2}, m \geq i, m \in \mathbb{N}\right\}$ for each $i \in \mathbb{N}$. Note that $T_{i_{k}}=T_{i}$ and $S_{i_{k}}=S_{i}$ whenever $k \in \mathbb{N}_{i}$. By Lemma 2.6 and the definition of $\mathbb{N}_{i}$, we have $\mathbb{N}_{1}=$ $\{1,2,4,7,11,16, \ldots\}$ and $i_{1}=i_{2}=i_{4}=i_{7}=i_{11}=i_{16}=\cdots=1$. Then it follows from (3.15) and (3.24) that

$$
\lim _{\mathbb{N}_{i} \ni k \rightarrow \infty}\left\|T_{i} x_{k}-x_{k}\right\|=\lim _{\mathbb{N}_{i} \ni k \rightarrow \infty}\left\|S_{i} x_{k}-x_{k}\right\|=0, \quad \forall i \in \mathbb{N} .
$$

It then immediately follows from (3.31) and (3.32) that $x^{*} \in F\left(T_{i}\right) \cap F\left(S_{i}\right)$ for each $i \in \mathbb{N}$ and hence $x^{*} \in F$.

Put $u=P_{F} x$. Since $u \in F \subset H_{n} \cap W_{n}$ and $x_{n+1}=P_{H_{n} \cap W_{n}} x$, we have $\phi\left(x_{n+1}, x\right) \leq \phi(u, x)$, $\forall n \in \mathbb{N}$. Then

$$
\phi\left(x^{*}, x\right)=\lim _{n \rightarrow \infty} \phi\left(x_{n+1}, x\right) \leq \phi(u, x),
$$

which implies that $x^{*}=u$ since $u=P_{F} x$, and hence $x_{n} \rightarrow x^{*}=P_{F} x$ as $n \rightarrow \infty$. This completes the proof.

Remark 3.2 Note that the algorithm (3.1) is based on the projection onto an intersection of two closed and convex sets. We first give an example [20] of how to compute such a projection onto the intersection of two half-spaces.

Let $H$ be a Hilbert space and suppose that $(x, y, z) \in H^{3}$ satisfies

$$
\{w \in H:\langle w-y, x-y\rangle \leq 0\} \cap\{w \in H:\langle w-z, y-z\rangle \leq 0\} \neq \emptyset .
$$


Set

$$
\pi=\langle x-y, y-z\rangle, \quad \mu=\|x-y\|^{2}, \quad \nu=\|y-z\|^{2}, \quad \rho=\mu \nu-\pi^{2},
$$

and

$$
Q(x, y, z)= \begin{cases}z, & \text { if } \rho=0 \text { and } \pi \geq 0 \\ x+(1+\pi / v)(z-y), & \text { if } \rho>0 \text { and } \pi v \geq \rho \\ y+(v / \rho)(\pi(x-y)+\mu(z-y)), & \text { if } \rho>0 \text { and } \pi v<\rho\end{cases}
$$

In [21], Haugazeau introduced the operator $Q$ as an explicit description of the projector onto the intersection of the two half-spaces defined in (3.34). He proved in [21] that the sequence $\left\{y_{n}\right\}$ defined by $y_{0}=x$ and

$$
(\forall n \in \mathbb{N}) \quad y_{n+1}=Q\left(x, Q\left(x, y_{n}, P_{B} y_{n}\right), P_{A} Q\left(x, y_{n}, P_{B} y_{n}\right)\right)
$$

converges strongly to $P_{C} x$.

Since the algorithm (3.1) involves the projection onto the intersection of two convex sets not necessarily half-spaces, we next give an example [22] to explain and illustrate how the projection is calculated in the general convex case.

Dykstra's algorithm Let $\Omega_{1}, \Omega_{2}, \ldots, \Omega_{p}$ be closed and convex subsets of $\mathbb{R}^{n}$. For any $i=$ $1,2, \ldots, p$ and $x^{0} \in \mathbb{R}^{n}$, the sequences $\left\{x_{i}^{k}\right\}$ are defined by the following recursive formulas:

$$
\left\{\begin{array}{l}
x_{0}^{k}=x_{p}^{k-1}, \\
x_{i}^{k}=P_{\Omega_{i}}\left(x_{i-1}^{k}-y_{i}^{k-1}\right), \quad i=1,2, \ldots, p, \\
y_{i}^{k}=x_{i}^{k}-\left(x_{i-1}^{k}-y_{i}^{k-1}\right), \quad i=1,2, \ldots, p,
\end{array}\right.
$$

for $k=1,2, \ldots$ with initial values $x_{p}^{0}=x^{0}$ and $y_{i}^{0}=0$ for $i=1,2, \ldots, p$. If $\Omega:=\bigcap_{i=1}^{p} \Omega_{i} \neq \emptyset$, then $\left\{x_{i}^{k}\right\}$ converges to $x^{*}=P_{\Omega}\left(x^{0}\right)$, where $P_{\Omega}(x):=\arg \inf _{y \in \Omega}\|y-x\|^{2}, \forall x \in \mathbb{R}^{n}$.

Note Another iterative method termed HAAR (Haugazeau-like Averaged Alternating Reflections) for finding the projection onto intersection of finitely many closed convex sets in a Hilbert space can be found in [20, Remark 3.4(iii)].

\section{Applications}

The so-called convex feasibility problem for a family of mappings $\left\{T_{i}\right\}_{i=1}^{\infty}$ is to find a point in the nonempty intersection $\bigcap_{i=1}^{\infty} F\left(T_{i}\right)$.

Note Although the problem mentioned above is indeed a convex feasibility problem, it is mainly referred to the finite case.

Let $E$ be a smooth, strictly convex, and reflexive Banach space, and $C$ be a nonempty, closed, convex subset of $E$. Let $\left\{B_{i}\right\}_{i=1}^{\infty}: C \rightarrow E^{*}$ be a sequence of $\beta_{i}$-inverse strongly monotone mappings, $\{\psi\}_{i=1}^{\infty}: C \rightarrow \mathbb{R}^{1}$ a sequence of lower semi-continuous and convex functions, and $\left\{\theta_{i}\right\}_{i=1}^{\infty}: C \times C \rightarrow \mathbb{R}^{1}$ a sequence of bifunctions satisfying the conditions:

$\left(\mathrm{A}_{1}\right) \theta(x, x)=0$ 
$\left(\mathrm{A}_{2}\right) \theta$ is monotone, i.e., $\theta(x, y)+\theta(y, x) \leq 0$;

$\left(\mathrm{A}_{3}\right) \lim \sup _{t \downarrow 0} \theta(x+t(z-x), y) \leq \theta(x, y)$;

$\left(\mathrm{A}_{4}\right)$ the mapping $y \mapsto \theta(x, y)$ is convex and lower semicontinuous.

A system of generalized mixed equilibrium problems (GMEP) for $\left\{\theta_{i}\right\}_{i=1}^{\infty},\left\{B_{i}\right\}_{i=1}^{\infty}$ and $\left\{\psi_{i}\right\}_{i=1}^{\infty}$ is to find an $x^{*} \in C$ such that

$$
\theta_{i}\left(x^{*}, y\right)+\left\langle y-x^{*}, B_{i} x^{*}\right\rangle+\psi_{i}(y)-\psi_{i}\left(x^{*}\right) \geq 0, \quad \forall y \in C, i \in \mathbb{N},
$$

whose set of common solutions is denoted by $\Omega:=\bigcap_{i=1}^{\infty} \Omega_{i}$, where $\Omega_{i}$ denotes the set of solutions to generalized mixed equilibrium problem for $\theta_{i}, B_{i}$, and $\psi_{i}$.

Define a countable family of mappings $\left\{S_{r, i}\right\}_{i=1}^{\infty}: E \rightarrow C$ with $r>0$ as follows:

$$
S_{r, i}(x)=\left\{z \in C: \tau_{i}(z, y)+\frac{1}{r}\langle y-z, J z-J x\rangle \geq 0, \forall y \in C\right\}, \quad \forall i \in \mathbb{N}
$$

where $\tau_{i}(x, y)=\theta_{i}(x, y)+\left\langle y-x, B_{i} x\right\rangle+\psi_{i}(y)-\psi_{i}(x), \forall x, y \in C, i \in \mathbb{N}$. It has been shown by Zhang [23] that

(1) $\left\{S_{r, i}\right\}_{i=1}^{\infty}$ is a sequence of single-valued mappings;

(2) $\left\{S_{r, i}\right\}_{i=1}^{\infty}$ is a sequence of closed relatively nonexpansive mappings;

(3) $\bigcap_{i=1}^{\infty} F\left(S_{r, i}\right)=\Omega$.

Theorem 4.1 Let E be a smooth, strictly convex, and reflexive Banach space, and $C$ be a nonempty, closed, convex subset of $E$. Let $\left\{T_{i}\right\}_{i=1}^{\infty}: C \rightarrow C$ be a sequence of relatively nonexpansive mappings and $\left\{S_{r, i}\right\}_{i=1}^{\infty}: C \rightarrow C$ be a sequence of mappings defined by (4.2) with $F:=\bigcap_{i=1}^{\infty}\left(F\left(T_{i}\right) \cap F\left(S_{r, i}\right)\right) \neq \emptyset$. Let $\left\{x_{n}\right\}$ be the sequence generated by

$$
\left\{\begin{array}{l}
x_{0}=x \in C, \quad H_{-1}=W_{-1}=C, \\
y_{n}=J^{-1}\left[\lambda_{n} J x_{n}+\left(1-\lambda_{n}\right) J z_{n}\right], \\
z_{n}=J^{-1}\left[\alpha_{n} J x_{n}+\beta_{n} J T_{i_{n}} x_{n}+\gamma_{n} J S_{r, i_{n}} x_{n}\right], \\
H_{n}=\left\{z \in H_{n-1} \cap W_{n-1}: \phi\left(z, y_{n}\right) \leq \phi\left(z, x_{n}\right)\right\}, \\
W_{n}=\left\{z \in H_{n-1} \cap W_{n-1}:\left\langle x_{n}-z, J x-J y\right\rangle \geq 0\right\}, \\
x_{n+1}=P_{H_{n} \cap W_{n}} x, \quad \forall n \in \mathbb{N} \cup\{0\},
\end{array}\right.
$$

where $\left\{\lambda_{n}\right\},\left\{\alpha_{n}\right\},\left\{\beta_{n}\right\}$ and $\left\{\gamma_{n}\right\}$ are sequences in $[0,1]$ satisfying

(1) $0 \leq \lambda_{n}<1, \forall n \in \mathbb{N} \cup\{0\} ; \lim \sup _{n \rightarrow \infty} \lambda_{n}<1$;

(2) $\alpha_{n}+\beta_{n}+\gamma_{n}=1 ; \lim _{n \rightarrow \infty} \alpha_{n}=0$ and $\liminf _{n \rightarrow \infty} \beta_{n} \gamma_{n}>0$;

and $i_{n}$ satisfies the equation $n=i_{n}+\frac{\left(m_{n}-1\right) m_{n}}{2}\left(m_{n} \geq i_{n}, n=1,2, \ldots\right)$. Then $\left\{x_{n}\right\}$ converges strongly to $P_{F} x$, which is some common solution to the convex feasibility problem for $\left\{T_{i}\right\}_{i=1}^{\infty}$ and a system of generalized mixed equilibrium problems for $\left\{S_{r, i}\right\}_{i=1}^{\infty}$. 


\section{Acknowledgements}

The authors are very grateful to the referees for their useful suggestions, by which the contents of this article has been improved. This study is supported by the National Natural Science Foundation of China (Grant No. 11061037).

Received: 22 February 2014 Accepted: 13 June 2014 Published: 22 July 2014

\section{References}

1. Butnariu, D, Reich, S, Zaslavski, AJ: Asymptotic behavior of relatively nonexpansive operators in Banach spaces. J. Appl. Anal. 7, 151-174 (2001)

2. Butnariu, D, Reich, S, Zaslavski, AJ: Weak convergence of orbits of nonlinear operators in reflexive Banach spaces. Numer. Funct. Anal. Optim. 24, 489-508 (2003)

3. Censor, Y, Reich, S: Iterations of paracontractions and firmly nonexpansive operators with applications to feasibility and optimization. Optimization 37, 323-339 (1996)

4. Matsushita, S, Takahashi, W: A strong convergence theorem for relatively nonexpansive mappings in a Banach space. J. Approx. Theory 134, 257-266 (2005)

5. Mann, WR: Mean value methods in iteration. Proc. Am. Math. Soc. 4(3), 506-510 (1953)

6. Reich, S: Weak convergence theorems for nonexpansive mappings in Banach spaces. J. Math. Anal. Appl. 67(2), 274-276 (1979)

7. Bauschke, HH, Matoušková, E, Reich, S: Projection and proximal point methods: convergence results and counterexamples. Nonlinear Anal., Theory Methods Appl. 56(5), 715-738 (2004)

8. Genel, A, Lindenstrauss, J: An example concerning fixed points. Isr. J. Math. 22(1), 81-86 (1975)

9. Nakajo, K, Takahashi, W: Strong convergence theorems for nonexpansive mappings and nonexpansive semigroups. J. Math. Anal. Appl. 279(2), 372-379 (2003)

10. Solodov, MV, Svaiter, BF: Forcing strong convergence of proximal point iterations in a Hilbert space. Math. Program., Ser. A 87(1), 189-202 (2000)

11. Plubtieng, S, Ungchittrakool, K: Strong convergence theorems for a common fixed point of two relatively nonexpansive mappings in a Banach space. J. Approx. Theory 149, 103-115 (2007)

12. Martinez-Yanes, C, Xu, HK: Strong convergence of the CQ method for fixed point iteration processes. Nonlinear Anal. 64, 2400-2411 (2006)

13. Su, Y, Qin, $X$ : Monotone CQ iteration processes for nonexpansive semigroups and maximal monotone operators. Nonlinear Anal., Theory Methods Appl. 68(12), 3657-3664 (2008). doi:10.1016/j.na.2007.04.008

14. Alber, Yl: Metric and generalized projection operators in Banach spaces: properties and applications. In: Kartosator, AG (ed.) Theory and Applications of Nonlinear Operators of Accretive and Monotone Type, pp. 15-50. Dekker, New York (1996)

15. Kohsaka, F, Takahashi, W: Block iterative methods for a finite family of relatively nonexpansive mappings in Banach spaces. Fixed Point Theory Appl. 2007, Article ID 21972 (2007)

16. Kamimura, S, Takahashi, W: Strong convergence of a proximal-type algorithm in a Banach space. SIAM J. Optim. 13, 938-945 (2002)

17. Cioranescu, I: Geometry of Banach Spaces, Duality Mappings and Nonlinear Problems. Kluwer Academic, Dordrecht (1990)

18. Zhou, HY, Guo, GT, Hwang, HJ, Cho, YJ: On the iterative methods for nonlinear operator equations in Banach spaces Panam. Math. J. 14, 61-68 (2004)

19. Deng, W-Q, Bai, P: An implicit iteration process for common fixed points of two infinite families of asymptotically nonexpansive mappings in Banach spaces. J. Appl. Math. 2013, Article ID 602582 (2013)

20. Bauschke, HH, Combettes, PL, Luke, DR: A strongly convergent reflection method for finding the projection onto the intersection of two closed convex sets in a Hilbert space. J. Approx. Theory 141, 63-69 (2006)

21. Haugazeau, Y: Sur les Inéquations Variationnelles et la Minimisation de Fonctionnelles Convexes, Thèse, Université de Paris, France (1968)

22. Boyle, JP, Dykstra, RL: A method for finding projections onto the intersections of convex sets in Hilbert spaces. In: Advances in Order Restricted Statistical Inference. Lecture Notes in Statistics vol. 37, pp. 28-47 (1986)

23. Zhang, SS: The generalized mixed equilibrium problem in Banach space. Appl. Math. Mech. 30, 1105-1112 (2009). doi:10.1007/s10483-009-0904-6 